\title{
PENGARUH PENERAPAN MODEL PEMBELAJARAN QUANTUM TEACHING TERHADAP PEMAHAMAN KONSEP MATEMATIKA SISWA KELAS VII MTS AL-IHSAN BULUH RAMPAI
}

\author{
Ramadhani Fitri ${ }^{1}$, Imas Siti Aminah ${ }^{2}$ \\ 1,2 STKIP Insan Madani Airmolek, Riau \\ ramadhanifitri190418@gmail.com ${ }^{1}$, imasaminah97@gmail.com²
}

\begin{abstract}
This study aims to determine students' mathematical Concept Understanding skills using the Quantum Teaching learning model. This research is a Quasi Experiment study with the design of the Randomized Subjects Posstest Only Control Group Design. The study population was all student of class VII MTs Al-Ihsan Buluh Rampai. The sampling technique uses random sampling. The instrument used was a mathematical concept Understanding ability test in the form of a descripsion
\end{abstract}

Keyword: Concept Understanding, Quantum Teaching

\section{Abstrak}

Penelitian ini bertujuan untuk mengetahui kemampuan pemaham konsep matematis siswa dengan menggunakan model pembelajaran Quantum Teaching. Penelitian ini meruapakan penelitian Quasi Experiment dengan rancangan Randomized Subject Posstest Only Control Group Design. Populasi penelitian yaituseluruh siswa kelas VII MTs Al-Ihsan Buluh Rampai. Teknik pengambilan sampel menggunakan Random sampling. Instrumen yang digunakan tes kemampuan pemahaman konsep matematis berupa uraian. Data dianalisis secara statistik dengan uji independent samples T-test. Berdasarkan hasil uji t tersebut, thitung berada di daerah penolakan $H_{0}$ dapat disimpulkan bahwa kemampuan pemahaman konsep matematis siswa yangh diajar dengan model pembelajaran Quantum Teaching lebih baik daripada pembelajaran konvensional.

Kata Kunci : Pemahaman Konsep, Quantum Teaching

Received: December 16, 2019 / Accepted: April 25, 2020 / Published Online: April 30, 2020 


\section{PENDAHULUAN}

Pendidikan adalah usaha sadar dan terencana untuk mewujudkan suasana belajar dan proses pembelajaran agar peserta didik secara aktif mengembangkan potensi dirinya untuk memiliki kekuatan spiritual keagaaman, pengendalian diri, kepribadian, kecerdasan, akhlak mulia, serta keterampilan yang diperlukan dirinya, masyarakat, dan Negara. Untuk mencapai tujuan pembelajaran matematika, dalam kegiatan pembelajaran perlu adanya suatu pembelajaran yang mampu mendorong siswa belajar secara aktif agar dapat belajar secara logis dan jujur, sehingga matematika dapat dengan mudah dipahami oleh siswa. Berhasil tidaknya pencapaian tujuan pembelajaran ditentukan oleh bagaimana proses pembelajaran yang dialami oleh siswa. Berdasarkan hasil pengamatan penulis lakukan di kelas VII MTs Al-Ihsan Buluh Rampai ditemukan permasalahan yaitu: Pertama, Pemahaman konsep matematis siswa kelas VII masih rendah. Terlihat ketika guru membahas contoh soal bersama dipapan tulis hanya beberapa siswa yang aktif bertanya dan menjawab. Kedua, ketika proses pembelajaran terlihat beberapa siswa sedang bercanda dengan temannya dan sibuk sendiri sehingga tidak serius dalam pembelajaran. Dan ketiga, Pemahaman konsep matematika siswa masih rendah, hal ini terlihat ketika guru memberikan soal yang berbeda dari contoh, masih banyak siswa yang salah ketika menyelesaikannya. Berdasarkan hasil analisis jawaban siswa dimana siswa hanya bisa menjawab tiga soal dengan benar dari enam soal yang diberikan, dan cara penyelesaiannya tidak memiliki alasan sesuai konsep sehingga tidak dapat diketahui dengan jelas dari mana datangnya jawaban yang diperoleh.

Dari permasalahan diatas, salah satu alternatif model pembelajaran yang memungkinkan dapat dijadikan sebagai solusi dalam meningkatkan pemahaman konsep siswa ialah dengan menggunakan model pembelajaran Team Quiz (Kuis Kelompok). Model pembelajaran Team Quiz (Kuis Kelompok) adalah model yang dapat meningkatkan tanggungjawab belajar peserta didik dalam suasana yang menyenagkan.

\section{METODE PENELITIAN}

Jenis penelitian ini adalah penelitian eksperimen. Penelitian eksperimen adalah suatu cara untuk mencari hubungan sebab akibat (hubungan kasual) antara dua faktor yang sengaja ditimbulkan oleh peneliti dengan mengeliminasi atau mengurangi atau menyisihkan faktor-faktor lain yang mengganggu.

Desain penelitian yang digunakan adalah Quasi Experimental Design dengan bentuk Randomized Subjects Posstest Only Control Group Design. 
Jurnal Lebesgue : Jurnal Ilmiah Pendidikan Matematika, Matematika dan Statistika

Ramadhani Fitri, Imas Siti Aminah

Volume 1, No. 1, April 2020 hal.49-55

Tabel 1. Bentuk Desain Randomized Subjects Posttest Only Control Group Design

\begin{tabular}{|c|c|c|c|}
\hline & Group & Variabel Terikat & posttest \\
\hline $\mathrm{R}$ & Experimen & $X$ & $Y_{2}$ \\
\hline $\mathrm{R}$ & Kontrol & - & $Y_{2}$ \\
\hline
\end{tabular}

Keterangan :
$\mathrm{R}:$ Randomisasi
$\mathrm{X}:$ Perlakuan
$Y_{2}:$ Posttest

Adapun sampel dalam penelitian ini adalah kelas VII.2 sebagai kelas eksperimen dan kelas VII.4 sebagai kelas kontrol. Instrumen dalam penelitian ini berupa tes pemahaman konsep matematika yang dilaksanakan diakhir (posttest) penelitian. Sebelum instrumen digunakan data terlebih dahulu diuji cobakan pada kelas selain kelas sampel yaitu kelas VII.3, guna mengetahui instrumen tersebut layak atau tidak untuk digunakan.

\section{HASIL PENELITIAN DAN PEMBAHASAN}

\section{Hasil Penelitian}

\section{Uji Normalitas}

Uji normalitas dilakukan dengan menggunakan software SPSS 22. Uji ini dilakukan bertujuan untuk melihat apakah sampel berdistribusi normal atau tidak. Uji ini dilakukan kepada kedua kelas sampel yaitu kelas eksperimen dan kelas kontrol. Hasil perhitungan uji normalitas kedua sampel dapat dilihat pada Tabel 3 berikut.

\section{Tabel 3. Hasil Perhitungan Uji Normalitas Kelas Sampel}

\begin{tabular}{lcc}
\hline \multicolumn{1}{c}{ Sampel } & Nilai Sig. & Keterangan \\
\hline Eksperimen & 0,200 & Normal \\
\hline Kontrol & 0,073 & Normal \\
\hline
\end{tabular}

Dari Tabel 3 terlihat bahwa nilai signifikan pada kelas eksperimen adalah 0,200 dan nilai signifikan pada kelas kontrol adalah 0,073. Karena signifikan pada kedua kelas sampel lebih besar dari $\alpha=0,05$ maka dapat disimpulkan bahwa kedua kelas sampel berdistribusi normal.

\section{Uji Homogenitas}

Uji homogenitas dianalisis dengan menggunakan software SPSS 22. Uji homogenitas bertujuan untuk melihat apakah kedua sampel mempunyai variansi yang homogen atau tidak. Hasil perhitungan uji homogenitas kedua sampel dapat dilihat pada Tabel 4 berikut.

Tabel 4. Hasil Perhitungan Uji Homogenitas Kelas Sampel

\begin{tabular}{cccc}
\hline Levene Statistic & $d f 1$ & $d f 2$ & Sig. \\
\hline 1.269 & 1 & 71 & .264
\end{tabular}


Jurnal Lebesgue : Jurnal Ilmiah Pendidikan Matematika, Matematika dan Statistika

Ramadhani Fitri, Imas Siti Aminah

Volume 1, No. 1, April 2020 hal.49-55

Berdasarkan Tabel 4 di atas, uji homogenitas variansi dengan statistik diperoleh signifikansi 0,264 , hasil analisis menunjukkan bahwa sig. $(0,264)>\alpha(0,05)$, berarti hipotesis nol nya diterima dengan kesimpulan bahwa kedua kelas sampel memiliki variansi yang homogen.

\section{Uji Hipotesis}

Setelah sampel berdistribusi normal dan memiliki variansi yang homogeny maka dilanjutkan dengan uji hipotesis dengan cara menggunakan Uji-t. Berdasarkan uji $t, t_{\text {hitung }}>t_{\text {tabel }}$ atau 1,257>-1,994 maka $\mathrm{H}_{0}$ ditolak. Jadi dapat disimpulkan bahwa "kemampuan pemahaman konsep matematika siswa dengan penerapan model pembelajaran Team Quiz (Kuis Kelompok) lebih baik dari pada kemampuan pemahaman konsep siswa yang memperoleh Pembelajaran Konvensional".

\section{Pembahasan}

Berdasarkan hasil penelitian yang telah dilakukan ternyata kemampuan pemahaman konsep matematika siswa yang di ajar dengan penerapan model pembelajaran Team Quiz (Kuis Kelompok) lebih baik dari pada kemampuan pemahaman konsep siswa yang memperoleh Pembelajaran Konvensional. Hal ini dikarenakan pada penerapan model pembelajaran Team Quiz (Kuis Kelompok) siswa dilatih untuk menyatakan ulang sebuah konsep, mengklasifikasi objek menurut tertentu sesuai dengan konsepnya, mengaplikasikan konsep atau algoritma dalam pemecahan masalah.

Berikut ini disajikan deskripsi dari bentuk-bentuk indikator kemampuan pemahaman konsep matematika siswa pada kelas eksperimen dan kelas kontrol yang diperoleh dari hasil tes akhir (posttest).

\section{a) Menyatakan ulang suatu konsep}

Kemampuan menyatakan ulang suatu konsep pada kelas sampel ditinjau dari hasil posttest siswa pada soal no. 3 berikut ini.

Soal no. 3

Perhatikan gambar ini!

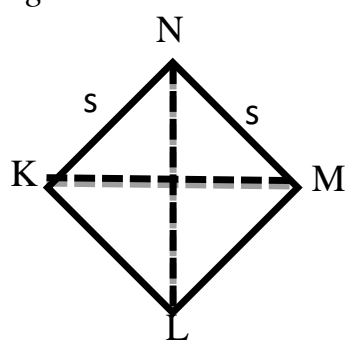

Coba turunkan rumus keliling dan luas bangun belah ketupat diatas!

Berdasarkan hasil analisis jawaban siswa kelas eksperimen dalam menjawab soal no. 3 terlihat bahwa siswa sudah dapat mengingat, memilih serta menyatakan konsep yang relevan dengan informasi, tujuan serta permasalahan yang diperoleh dari soal.

Dalam proses pengorganisasian dan pemilihan konsep itu sendiri didasari kemampuan siswa dalam melakukan keterkaitan antar konsep. 
Jurnal Lebesgue : Jurnal Ilmiah Pendidikan Matematika, Matematika dan Statistika

Ramadhani Fitri, Imas Siti Aminah

Volume 1, No. 1, April 2020 hal.49-55

Berdasarkan hasil analisis jawaban siswa kelas kontrol soal no. 3 dimana siswa bisa menjawabnya dengan benar, namun cara penyelesaiannya berbeda dengan kelas eksperimen yang jawabanya memiliki alasan sesuai konsep sehingga dapat diketahui dengan jelas dari mana datangnya jawaban yang diperoleh. Perbedaan terlihat pada turunan rumus luas belah ketupat di atas. Perbedaan ini dikarenakan siswa kelas kontrol belum dapat menyatakan konsep dengan lebih lengkap dan jelas namun sebagian jawaban yang benar sudah menunjukkan bahwa siswa kelas kontrol memahami keterkaitan konsep misalnya keterkaitan penggunaan aturan menurunkan rumus dengan persoalan yang dihadapinya. Dari deskripsi jawaban siswa kelas eksperimen dan kontrol, terlihat bahwa kemampuan menyatakan ulang suatu konsep matematika pada kelas eksperimen lebih baik dari pada kelas kontrol.

\section{b) Mengklasifikasi objek menurut sifat tertentu sesuai dengan konsepnya}

Mengklasifikasi objek menurut sifat tertentu sesuai dengan konsepnya dapat ditinjau dari hasil posttest siswa kelas sampel pada no. 1 dan 2 berikut ini.

Soal no. 1

Perhatikan gambar dibawah ini, tentukan bangun yang berbentuk belah ketupat, layanglayang, dan trapesium. Kemudian sebutkan sifat-sifat dari bangun tersebut! masing-masing 2 sifat!



(a)

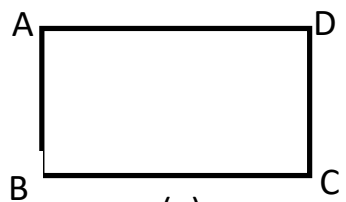

(e)

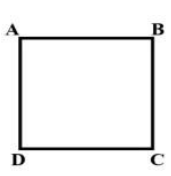

(b)

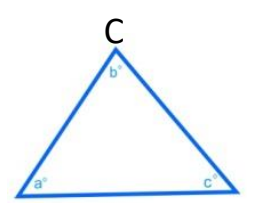

A

(c)

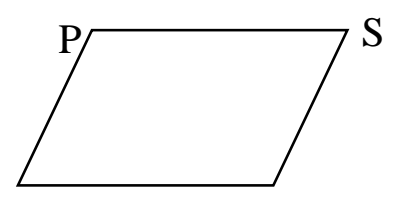

(d) $\quad R$

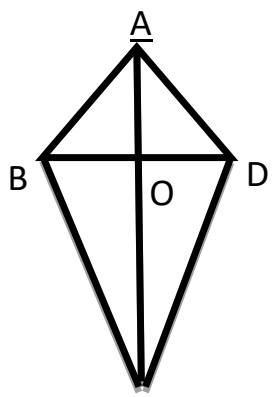

(g)

Berdasarkan hasil analisis jawaban siswa kelas eksperimen dalam menjawab soal no.1 terlihat bahwa siswa dapat mengklasifikasi suatu objek dan pemilihan konsep itu sendiri didasari oleh kemampuan siswa dalam melakukan keterkaitan antar konsep. Disamping itu proses berpikir siswa lebih terarah dan konseptual, sehingga mencapai hasil akhir yang benar. Hal ini terlihat pada jawaban siswa, dimana siswa dapat menjawab soal beserta keterangan memperoleh hasil matematika dengan benar sesuai konsep sehingga dapat memberikan jawaban dengan jelas dan benar.

Berdasarkan hasil analisis jawaban siswa kelas kontrol dalam menjawab soal no. 1 dimana siswa bisa membedakan segiempat, namun kurang tepat dalam menyebutkan sifat-sifat segi empat tersebut. Hal 
Jurnal Lebesgue : Jurnal Ilmiah Pendidikan Matematika, Matematika dan Statistika

Ramadhani Fitri, Imas Siti Aminah

Volume 1, No. 1, April 2020 hal.49-55

ini dikarenakan siswa belum dapat memahami konsep dengan maksimal yang dapat mengakibatkan siswa tidak dapat menentukan atau menyusun langkah berikutnya secara terstruktur dan jelas.

\section{c) Mengaplikasikan konsep atau algoritma dalam pemecahan masalah}

Mengaplikasikan konsep atau algoritma dalam pemecahan masalah dapat ditijau pada posttest no. 4 berikut ini.

Soal no. 4

Luas sebuah layang-layang adalah $450 \mathrm{~cm}^{2}$ dan panjang salah satu diagonalnya $18 \mathrm{~cm}$. Panjang diagonal lainnya adalah...

Berdasarkan hasil analisis jawaban siswa kelas eksperimen dalam menjawab soal no. 4 terlihat proses berpikir siswa lebih terarah dan sistematis, sehingga mencapai hasil akhir yang benar. Hal ini terlihat pada jawaban siswa, dimana siswa dapat menjawab soal beserta keterangan memperoleh hasil matematika dengan benar sesuai konsep sehingga dapat memberikan jawaban dengan jelas dan benar

Berdasarkan hasil analisis jawaban siswa kelas kontrol dalam menjawab soal no. 4 dimana siswa bisa menjawab dengan benar dalam menentukan rumus luas layang-layang, namun dalam tidak dapat menyelesaikannya. Hal ini dikarenakan siswa belum memahami cara mengaplikasikan konsep dengan tepat ketika dihadapkan dengan permasalahan yang berbeda diatas. Maka dapat disimpulkan berdasarkan jawaban siswa kelas eksperimen dan kelas kontrol bahwa kelas eksperimen lebih baik dari kelas kontrol.

Soal no. 5

Sebuah trapesium mempunyai luas $60 \mathrm{~cm}^{2}$ dan tinggi $6 \mathrm{~cm}$. Perbandingan sisi sejajar adalah $2: 3$, panjang sisi sejajar terpendek adalah...

Berdasarkan hasil analisis jawaban kelas eksperimen dalam menjawab soal no. 5 dimana siswa mampu menggunakan konsep luas trapesium yang diaplikasikan kedalam soal yang harus dipecahkan dan menyusun langkah-langkah konsep secara algoritma atau terurut sehingga mendapatkan jawaban yang terstruktur, jelas, dan benar. Hal ini terlihat pada jawaban siswa, dimana siswa dapat menjawab soal beserta keterangan memperoleh hasil matematika dengan benar sesuai konsep sehingga dapat memberikan jawaban dengan jelas dan benar.

Berdasarkan hasil analisis jawaban siswa kelas kontrol dalam menjawab soal no. 5 dimana siswa bisa menjawab dengan benar, namun jawaban siswa kurang lengkap artinya siswa belum mampu menyelesaikan soal sampai akhir. Hal ini dikarenakan siswa belum memahami cara mengaplikasikan konsep dengan tepat ketika dihadapkan dengan permasalahan yang berbeda diatas. Maka dapat disimpulkan berdasarkan jawaban siswa kelas eksperimen dan kelas kontrol diperoleh bahwa kelas eksperimen lebih baik dari kelas kontrol.

Berdasarkan hasil analisis jawaban tes kemampuan pemahaman konsep matematika siswa dari deskripsi tiap-tiap indikator yang dipilih maka diperoleh hasil bahwa kemampuan pemahaman konsep kelas eksperimen lebih tinggi daripada kemampuan pemahaman konsep kelas kontrol. Hal ini 
Jurnal Lebesgue : Jurnal Ilmiah Pendidikan Matematika, Matematika dan Statistika

Ramadhani Fitri, Imas Siti Aminah

Volume 1, No. 1, April 2020 hal.49-55

juga sesuai dengan hipotesis pada penelitian ini, yaitu "Kemampuan pemahaman konsep siswa dengan penerapan model pembelajaran Team Quiz (Kuis Kelompok) lebih baik daripada kemampuan pemahaman konsep matematika siswa dengan pembelajaran konvensional".

\section{KESIMPULAN}

Berdasarkan hasil penelitian pengujian hipotesis terhadap kedua kelas sampel di peroleh nilai $P$-value lebih kecil dari $a$, yaitu $0,000<0,05$. Artinya bahwa $\mathrm{H}_{0}$ ditolak dan $\mathrm{H}_{\mathrm{a}}$ diterima. Dengan demikian dapat disimpulkan bahwa kemampuan pemahaman konsep matematis siswa yang diajar dengan model pembelajaran Quantum Teaching lebih baik daripada pembelajaran pada kelas VII MTs Al-Ihsan Buluh Rampai.

Bagi peneliti dapat mengembangkan model pembelajaran Quantum Teaching untuk melihat kemampuan matematis lainnya seperti kemampuan komunikasi matematis, penalaran dan pemecahan masalah matematika.

\section{DAFTAR PUSTAKA}

Arikunto, Suharsimi, 2013. Dasar-Dasar Evaluasi Pendidikan, Bumi Aksara, Jakarta,.

Darmadi, Hamid, 2013. Metode Penelitian dan sosial, Alfabeta, Bandung,. , 2013.Prosedur Penelitian, Pt Rineka Cipta, Jakarta,.

Hamzah, Ali dan Muhlisrarini, 2014. Perencanaan dan Strategi Pembelajaran Matematika, PT Raja Grafindo Persada, Jakarta,.

Istarani, 2014.58 Model Pembelajaran Inovatif, Media Persada, Medan,

Trianto, 2009. Mendesain Model Pembelajaran Inovatif-Progresif, Kencana Prenada Media Group, Jakarta,

Priyatno, Duwi. 2014. SPSS 22 Pengolahan data terpraktis. Yogyakarta : penerbit ANDI.

Wardhani, Sri, 2008. Analisis SI dan SKL Mata Pelajaran Matematika SMP/MTs untuk Optimalisasi Tujuan Mata Pelajaran Matematika, PPPPTK Matematika, Yogyakarta 